\title{
O DOCUMENTÁRIO COMO INSTRUMENTO NA EDUCAÇÃO PARA COMBATER O PRECONCEITO DE GÊNERO: O CASO MARIA LUISA
}

\author{
V. RHODEN ${ }^{1}$, J. D. SILVA ${ }^{2}$, V. M. F. OLIVEIRA ${ }^{3}$ \\ Universidade Federal de Santa Maria \\ vrhoden6@gmail.com ${ }^{1}$
}

Artigo submetido em 24/09/2018 e aceito em 24/06/2019

DOI: $10.15628 /$ holos.2019.7789

\section{RESUMO}

A proposta deste artigo é trazer discussão sobre a importância que o documentário pode ter na educação como ferramenta de conscientização no ambiente escolar, para diminuir o preconceito na questão de gênero. Além de pesquisa bibliográfica, tem amparo do documentário Maria Luisa, idealizado pelo GEPEIS da UFSM e que teve seu propósito nesta perspectiva. A educação pode e deve utilizar-se de diferentes ferramentas para difundir pautas importantes atualmente, e com o instrumento audiovisual, seu alcance e influência podem ser ainda maiores. Cabe ao educador estimular o criticismo nos ambientes nos quais atua, por meio da diversidade de informação e dos questionamentos do status quo vigente.

PALAVRAS-CHAVE: Cinema, Documentário, Educação, Preconceito.

\section{THE DOCUMENTARY AS AN INSTRUMENT IN EDUCATION TO COMBAT GENDER PRECONCEPTION: THE CASE MARIA LUISA}

\begin{abstract}
The purpose of this article is to discuss the importance documentary movies can have in education as a tool for raising awareness in the school environment, in order to reduce prejudice on the issue of gender. In addition to bibliographical research, it has support of the documentary Maria Luisa, idealized by GEPEIS of UFSM and that had its purpose in this perspective. Education
\end{abstract}

can and should use different tools to disseminate important guidelines, and with the audiovisual instrument, its scope and influence may be even greater. It is up to the educators to stimulate criticism in their environment of work, through the diversity of information and the questioning of the current status quo.

KEYWORDS: Cinema, Documentary, Education, Preconcept. 


\section{APRESENTAÇÃO}

Dentro dos espetáculos do mundo moderno, como trazer a atenção a um tema sensível e pungente, mas banalizado pelo cotidiano? Os noticiários em jornais e os vislumbres do dia-a-dia dessensibilizam o senso crítico, fazendo com que algo incomum seja visto como o normal. Assim, prolifera-se o preconceito em várias frentes, incluindo aí as questões de gênero, como agressões e violência.

Cabe ao docente trazer criticismo nos ambientes em que atua, e o cinema-documentário acaba por ser um meio extremamente prolífico para o estímulo a essas discussões. O documentário Maria Luisa tem a especificidade de tratar da situação de uma mulher trans que, quando jovem, foi um garoto criado em meio à cultura gaúcha de fronteira: peculiaridade esta que permeia vários ambientes, incluindo o escolar. Neste sentido, embora acolhida por alguns professores, em seu modo de agir trazia olhares reprovadores de colegas e de uma parte da comunidade escolar.

Após sair da cidade, assumir-se transexual e retornar em 2015 para estudar no ensino tecnológico - esperava encontrar uma cidade menos preconceituosa devido ao cosmopolitismo de um ambiente acadêmico - já que passou quase duas décadas da sua saída. Porém, sofreu, novamente, rejeição no ambiente acadêmico, o que estimulou a produção de um documentário que trouxesse à tona sua história para a conscientização da presença da diversidade sexual no ambiente universitário, e como conviver com ela.

\subsection{Conceitos e tipos de documentários}

Documentário, como mostra seu radical, tem o peso ou caráter de um documento. Logo, via de regra, trata-se de algo não-ficcional-embora muito se discuta, no campo da Comunicação Social, sobre a(s) estética(s) possível(is) da mídia. Quais são os limites da realidade? Uma vez que cada ponto de vista é sempre uma narrativa pessoal, e logo, não há verdade objetiva (Ramos \& Catani, 2001). A primeira vez que o termo 'documentário' foi usado, foi pelo escocês John Grierson nos idos de 1930. Este documentarista se interessava pelos problemas sociais da referida década, como a transição do modernismo, a pobreza, os subempregos, etc., apropriando-se de questões pontuais de fragilidade social.

Ou, ainda, Ramos enseja que o documentário "pode ser definido, de forma breve, como uma narrativa que estabelece enunciados sobre o mundo histórico" (Ramos, 2004, p.163), traço marcante que o separa da narrativa de ficção. $\mathrm{O}$ autor coloca que todo documentário vem carregado de intenções do diretor, que normalmente traz um tema que repercute socialmente.

Ao entrarmos no cinema, na locadora ou quando sintonizamos o canal a cabo, sabemos de antemão se o que vemos é uma ficção ou um documentário. A intenção documentária do autor/cineasta, ou da produção do filme, é indexada através de mecanismos sociais diversos, direcionando a recepção (Ramos, 2008, p.27). 
Assim, há abordagens de cunho educativo, científico, policial, estilo de vida, etc. Ou ainda, versões parciais de fatos subjetivos com interesse social, interligando idealizador e público espectador por meio dos fatos a serem narrados visualmente e dos atores-viventes das situações. "Os documentários dão densidades discursivas [...] ao comportamento social [...], aos mundos invisíveis e aos personagens incertos. Marca mazelas e delícias de se viver o contemporâneo" (Bodstein, 2016, p.02). É uma mídia visual das mais efetivas para a produção de sensibilidades sobre o tema escolhido, produzindo grande engajamento quando utilizada na forma pedagógica, pois "produz efeitos de sínteses culturais acerca de quem somos no contexto que herdamos e reconstruímos para asseverar nossa existência" (idem).

Segundo Nichols (2005), existem seis tipos de documentários: poético, expositivo, observativo, participativo, reflexivo e performativo. Esta classificação se dá em razão dos usos, estilos e objetivos pensados para a peça a ser criada, mas não se trata de uma denominação estanque, pois mais de um estilo podem coexistir na criação:

- Poético: não necessita uma montagem linear e pode descolar-se de uma realidade literal. Seu objetivo é causar emoções e, por isso, pode ser fragmentado e sem a necessidade de situar tempo, espaço, pessoas. Trata muito mais da visão do documentarista sobre algum aspecto do mundo.

- Expositivo: faz uma correlação de fatos buscando argumentos para criar uma construção que informe o espectador. Pode fazer uso de legendas, narrativas com voz over (por cima de um áudio original) ou voz off (voz de narrador), que não são identificadas como alguém presente na peça de vídeo, mas sim, como um conhecedor do todo que é ouvido, mas não, visto. As imagens vêm como referência do que é dito. Logo, há grande coerência informativa e confiabilidade entre o dito e o mostrado.

- Observativo: busca-se a realidade fidedigna, literal, assim como aconteceu de fato. As cenas devem ser autoexplicativas e sem interferências de interpretação - seja por um narrador ou por trilha sonora. O documentarista e sua equipe devem ser 'ignorados' pelos demais, e assim, traz a pretensão de neutralidade e desinteresse naquilo que é captado, como se tudo fosse natural. Não há intervenção e a câmera é meramente uma testemunha do que acontece. Cabe ao público fazer sua interpretação pessoal.

- Participativo: é mostrada a participação do documentarista e da equipe, no sentido da direção e intervenção no filme. Logo, ficam evidentes as ações sobre o que está acontecendo e sendo gravado. Fica mais evidente a proposta do documentarista, e também há mais presença de entrevistas guiadas pelo documentarista.

- Reflexivo: os membros da equipe e a montagem, o 'por trás das câmeras', também estão presentes nesta forma de documentário. Também se evidencia a relação que é desenvolvida entre documentarista(s) e documentados, reações do grupo pesquisado, etc. Assim, potencializa-se o poder de envolvimento dos espectadores, que são chamados a um envolvimento mais palpável (tomada de atitude) após o término do documentário. 
- Performativo: o destaque neste formato é o padrão estético que faz uso de muitos recursos cinematográficos (vídeo-arte). Embora faça uso de recursos de estilo, não deixa de lado a racionalidade e a combina com aspectos do imaginário estudado, enfatizando a complexidade psicológica dos envolvidos; assim, conduz pelo emocional. É preciso cuidado do documentarista para não intercruzar aspectos pessoais de forma a desfocar o relato principal. Traz características do cinema experimental e de vanguarda, uma vez que une elementos de narrativas de ficção como metáforas para elementos subjetivos do tema estudado.

Ramos (2008) aborda a classificação de documentário de uma forma mais histórica ou cronológica em termos de amadurecimento do formato, com destaque para:

- Clássico: correlato ao documentário expositivo, ou seja, o padrão vigente até os anos 1960, com narrações e alto teor de convencimento.

- Moderno: análogo ao documentário participativo, em que fica clara a intenção ideológica do documentarista, sua condução e a intencionalidade do produto audiovisual por meio das intervenções na narrativa.

Há, ainda, situações de oportunidade única - por exemplo, um festejo ou evento - e registrálos traz a epítome de uma realidade objetiva. Em outras situações, pode ser solicitado que o indivíduo filmado repita um gesto ou uma fala de modo a tornar o registro mais claro e compreensível. Deve-se destacar, ainda, que todo documentário é uma peça de convencimento e, por isso, pode ser enviesada (mostrando apenas a parte que interessa de um posicionamento favorável ou contrário a dado assunto).

Estas ações suscitam, ainda hoje, discussões sobre o quão fidedigna é uma peça de mídia que se pretende reprodutora de uma realidade, mas que se dá o direito de reprodução desta mesma realidade de uma forma 'mais bonita' para melhor apreensão pela câmera. Porém, compreende-se, aqui, que a realidade continua inalterada no seu cerne, e mesmo quando adequada para melhor representação, os fatos em si não mudam. A realidade readequada não dá falso testemunho sobre ela mesma, mas sim, amplia a objetividade da informação a ser transmitida.

A busca do outro é o cerne do documentário, e do que é digno de nota no outro, deslocando o documentarista em uma experiência a um mundo diferente do seu. Neste sentido, o documentarista, ao escolher esse mundo do diferente, que irá retratar, também põe muito de si. Afinal, isto é o que motiva a sua escolha e o direcionamento do seu olhar, ou seja, aquilo que lhe toca. Segundo Marcato (2014, p.02), "as biografias permitem ao público uma viagem a outros contextos históricos e culturais através de um relato de uma vida em sua singularidade, um registro histórico da memória pessoal e coletiva de um indivíduo".

\subsection{Metodologia}

Além de pesquisa bibliográfica, o artigo contou com o amparo da análise do documentário produzido pelo Grupo de Estudo e Pesquisa em Educação e Imaginário Social (GEPEIS), sobre a persona Maria Luisa, e ainda com a entrevista realizada com a protagonista para entender a produção e, ao mesmo tempo, o propósito do mesmo aplicado na educação. 


\section{O DOCUMENTÁRIO NA EDUCAÇÃO}

Sendo 'documentário' o nome dado a uma produção visual de não-ficção (um ponto de vista de uma realidade específica), convida à imersão em um assunto pelo entendimento daqueles diretamente envolvidos no tema. Na Educação, esta ferramenta traz, necessariamente, reflexões e criticismos sobre os papeis do professor, das autoridades e dos valores sociais enfatizados no sistema escolar.

Considerando-se a geração nascida principalmente a partir dos anos 1900, tem-se nas mídias visuais e fílmicas um grande aporte informativo. Com plataformas específicas para vídeos na internet (ex.: You Tube), popularizou-se a produção independente de material para esses meios, aliada a acesso e custos facilitados na aquisição de equipamentos para gravação e edição. Logo, a aproximação a um grande público de interesse por meio do uso de documentários torna-se uma escolha natural quando se trata da divulgação de uma mensagem no ambiente escolar e acadêmico. O formato cinema-documentário, desde os anos iniciais, permite que sejam conduzidas vivências de imersão:

O que se constata é que a nova linguagem se apresenta, desde o início, como um terreno bastante apropriado para a narrativa biográfica, primeiro, com a força da imagem em movimento e, mais tarde, com a sua conjugação com o som. A especificidade da linguagem audiovisual oferece uma forma privilegiada, em relação a outras linguagens, de construir e revelar histórias de vidas. (Cruz, 2011, p. 27)

Com o objetivo de ressignificação de mentalidades de preconceito, o documentário tem se mostrado bastante efetivo no campo educacional, por publicizar uma interiorização da persona em tela. Esse indivíduo tem a oportunidade de pautar seu cotidiano de forma coletiva, colocando-se essencialmente como um cidadão como qualquer outro, que deseja seu lugar no mundo e sua aceitação social sem o intuito de 'ofender' ninguém. É a expressão do ethos sem máscaras, e que muitas vezes, pode incomodar terceiros, justamente pela sua honestidade.

Percebe-se que existirá sempre um posicionamento prévio do documentarista em inserir socialmente este indivíduo que se expressa. $O$ espectador é convidado a ocupar a cadeira ou o lugar de avaliador de uma realidade diversa da sua.

O campo do documentário (vem) articulado com o surgimento de um modelo específico de comportamento diante da imagem cinematográfica, modelo este que tem uma estrutura histórica e que se vincula a determinadas redes sociais, culturais, estéticas e econômicas. [...] O cinema é aqui a cena onde o poder - de ver, saber, julgar - se expõe à crítica, à medida que se é juiz da representação que tal personagem, tal instituição, tal poder dão de si mesmos (França, 2010, p.02) 
Bernardet (1985) traz a configuração dos chamados 'tipo sociológico' e do 'modelo sociológico'. Estes vêm a fazer a representatividade social de um determinado padrão de comportamento retratado em um documentário como exemplo peculiar, mas ao mesmo tempo, de aceitação. Os documentaristas que optam por esta variante buscam colocar a sua produção a serviço de uma mudança social - principalmente por meio da quebra de muros imaginários construídos em razão do preconceito. $O$ documentário, após finalizado, torna-se produto científico e de divulgação de comportamento e vivência. Neste sentido, diz Bernardet:

Para que passemos do conjunto das histórias individuais à classe e ao fenômeno, é preciso que os casos particulares apresentados contenham os elementos necessários para a generalização, e apenas eles. [...] Essa limpeza do real condicionada pela fala da ciência permite que o real expresse o particular, que o particular sustente o geral, que o geral saia de sua abstração e se encarne, ou melhor, seja ilustrado por uma vivência. (Bernardet, 1985, p.15)

O cinema, enquanto recurso pedagógico é frequentemente utilizado na sala de aula com crianças para fins recreacionais, e para jovens, como complemento escolar de conteúdo. Já no ensino superior, pode cumprir com estas aplicações funcionais, mas também com outras, de cunho de formação social de massa crítica. Fischer (2007) diz que "talvez um dos trabalhos pedagógicos mais revolucionários seja o que se refere a uma ampliação do repertório de professores, crianças e adolescentes, em matéria de cinema, televisão, literatura, teatro, artes plásticas e música" a fim de "ampliar as possibilidades de estabelecer relações [...] para pensar de outro modo o presente que vivemos" (Fischer, 2007, p. 298). Muitas vezes o docente se depara com a realidade dicotomizada em sala de aula, daquilo que é bonito ou feio, o que deve e o que não deve, que nada passam de imposições sociais que fazem a manutenção do status quo e, assim, são continuamente repassadas. "O cinema, ao apresentar essas diferentes formas de retratar o ser humano, contribui para o entendimento de questões do inconsciente que não se enquadram na racionalidade pretendida pelo pensamento moderno" (Siqueira, Oliveira \& Braga, 2005, p.05), pois o indivíduo pós-moderno é muito mais complexo do que as conceituações ainda remanescentes na sociedade.

\section{FALANDO UM POUCO DO DOCUMENTÁRIO DE MARIA LUISA}

O documentário Maria Luisa se trata do estudo de caso de vivências da transexualidade, do ponto de vista de uma mulher trans que exerce suas atividades em uma cidade fronteiriça no estado do Rio Grande do Sul, Brasil. É sabido que as tradições culturais de fronteira costumam ser bastante machistas, pois valorizam a masculinidade necessária às relações interterritoriais. Maria Luisa também vem-se movendo em dois terrenos muito movediços, e precisou construir sua identidade com muita clareza, para sentir-se apta ao retorno ao lar. Embora haja trechos com características diversas, este documentário melhor se enquadra no formato reflexivo. 
Segundo Nichols, "o modo reflexivo é o modo de representação mais consciente de si mesmo e aquele que mais se questiona" (Nichols, 2005, p. 166). Por suscitar uma tomada de atitude na forma de mudança de pensamento, serve como motriz de uma mudança social nos ambientes escolares aos quais se destina - seja para o empoderamento de indivíduos diretamente envolvidos nas questões de gênero; seja na mudança da mentalidade baseada em pré-conceitos estigmatizados.

Saindo da cidade de São Borja ainda na adolescência, passou por etapas que ainda são muito tênues na identificação de limites. Mesmo dentro do(s) movimento(s) LGBTS, há muita disparidade na compreensão e aceitação das variadas facetas da complexa sexualidade humana. Nos anos 1980, essa conceituação se resumia em 'heterossexualidade' ou 'homossexualidade', ou seja, tais conceitos são recentes a toda a sociedade, inclusos ambos os grupos citados.

O documentário se dirige a dois públicos distintos - acadêmicos e comunidade LGBTS -, evidenciando uma base comum de resposta sensível e acolhedora. $\mathrm{O}$ empoderamento acontece também aos heterossexuais que passam a se sentir mais seguros em como agir com relação aos demais, derrubando muros psicossociais e construindo pontes de compreensão. A partir do momento em que ocorre o convite ao julgamento por si, o espectador não tem mais a justificativa de distanciamento pela ignorância:

(Os documentários) devolvem à condição do espectador das imagens cotidianas um outro lugar, mais interrogante e menos ludibriado pela ilusão de ocupar o lugar daquele que sabe, classifica, julga e decide. Menos predisposto a se instalar no puro voyeurismo ou na completa indiferença, tão comum no sensacionalismo das notícias, no sentimentalismo das telenovelas, na espetacularização dos programas de variedades televisivos, o espectador nestes filmes se vê capturado por outras demandas que implicam ambiguidades, contradições, repetições e afetos paradoxais (França, 2010, p.12).

Ao retornar a São Borja para estudar, inevitável que a memória e os afetos do passado afluíssem novamente. Porém, pela expectativa da atuação em uma instituição de nível superior, a abordagem preconceituosa deveria ter-se tornado algo do passado, afinal, conhecimento e preconceito são elementos antagônicos.

\subsection{O preconceito social de Maria Luisa começou na escola e continuou na academia}

Maria Luisa sofria com agressões verbais e físicas dos colegas, quando ainda era um menino com menos de 10 anos. A coordenadora pedagógica percebeu a situação e chamou-o para conversar. Apesar de ter sido esta professora a falar com Maria Luisa e feito com que ela se entendesse melhor, esta ainda passou por situações que a marcaram:

Como eu falava em escola, teve um momento que estávamos brincando de caçador, se não me engano e um menino me chamou de putinha, viadinho, mariconinha, e eu não sei o que me deu no momento, eu explodi, eu não vou mais suportar isto, eu me sentei, a professora 
Vera, que até hoje é docente. Ai ela chamou a atenção dele - mandou ele pra direção e eu para a biblioteca, a partir daquele momento eu não fiz mais educação física, eu ia para biblioteca ler, ou pra secretaria. Isto era um alivio. Aí lembro que teve outro momento com este momento. Fizeram um corredor polonês no recreio - eles passavam a mão na minha bunda, e percebi que era o bullying, então foi acontecendo, fiquei chateado. Comentei isto e o cara disse que ia me pegar na saída e dito e feito, ele estava lá. Pra briga nunca gostei, para argumentar sim, mas ele queria brigar. (Gelatti, 2017, p.02)

Neste sentido, é essencial trabalhar a questão de gênero nas escolas para diminuir o preconceito e bullying. A OMS (Organização Mundial de Saúde), em 1990, retirou a homossexualidade da lista internacional de doenças ${ }^{1}$. O Brasil, por meio do Conselho Federal de Psicologia, deixou de considerar a opção sexual como doença ainda em 1985, antes mesmo da resolução da OMS.

Estas dificuldades continuaram depois, no ensino tecnológico. O nome social foi solicitado e incluído na instituição de ensino. O estudo foi algo importante na trajetória da Maria Luisa, mesmo tendo enfrentado preconceito de onde menos esperava: de um professor:

Quando passei, me muni com os documentos para que fosse incluído meu nome social. Ai a menina foi muito simpática - apresentei uma portaria do Instituto Federal Farroupilha de Santa Catarina e resolução da Secretaria da Educação. Aí viram que eu não era desinformada, eu tinha informações. Ai, tudo bem, o pedido foi feito, mas a chamada ainda era feita pelo nome civil e os professores falavam: o Éwerton ainda não veio? O meu receio era como as pessoas iam aceitar isto, os colegas. Achei que os professores iam entender, mas foi o contrário. Me tornei líder da turma, delegava funções para todos, não era ninguém sozinha, eu tinha um professor que não gostava, mas terminou o primeiro semestre. No segundo começava a pegar no pé da gente, com deboche. Aí falei para meu amigo - a gente vai se formar e mostrar para ele. Eu não fiquei em exame, meu amigo ficou. A gente tem que se superar, pra gente e para os outros. Grande parte vê isto - você tem que se superar, em eventos também, 'e o fato de ser trans, será que tem capacidade?'e aí você mostra isto, todo mundo é igual. Eu sei que o professor pegou no nosso pé e nós pegamos no pé dele. Não pode ter estudo e ter preconceito. (Gelatti, 2017, p.10)

Neste sentido, um documentário pode ser instrumento de apoio ao professor num processo educativo. O/A docente é aquele que possui uma prática que tende a desenvolver junto aos/às estudantes uma capacidade crítica, esse/a professor/a caminha por uma direção emancipadora, consciente de constituir-se constantemente a partir de uma curiosidade construída pela superação de sua curiosidade ingênua, capaz de compreender sua função e o mundo criticamente, com o propósito de romper com verdades rotuladas socialmente que podem gerar preconceitos, discriminações e estereótipos.

\footnotetext{
${ }^{1}$ Fonte: Site Terra, disponível em: <goo.gl/NVJZmr>. Acesso em: 01 mar. 2018.
} 


\subsection{O documentário da Maria Luisa como instrumento de conscientização}

O propósito de mostrar a trajetória de vida da Maria Luisa através de um documentário não foi o de enaltecer as várias barreiras que ela teve de vencer na família, sociedade, amigos, escola/academia e no trabalho. Mas, sim, para servir como um instrumento educacional a encorajar outras pessoas que passam por situações parecidas a vencer barreiras que muitas vezes são reflexo de uma sociedade preconceituosa e, acima de tudo, com falta de informação.

Eu não luto só pela classe LGBT, eu luto por todas as classes. Acho que quando eu luto por um negro LGBT, de periferia, luto por uma educação que falta muito no país, pois falta conhecimento, são manipulados por uma informação que é distorcida. [...] A gente tem que se respeitar e respeitar o outro, ter empatia, colocar-se no lugar do outro, e de querer ajudar os outros - fazer algo por alguém, sem pensar num retorno - e assim, possa ter um mundo melhor. Ter multi-família, com anã, dois pais, cadeirante, casal normal [...], com direitos humanos para todo mundo. (Gelatti, 2017, p.08)

Percebe-se aqui que tais falas só podem ganhar repercussão quando vêm em como uma mídia (audiovisual) de mais fácil aceitação das novas gerações para que não reproduzam comportamentos errôneos. É na escola em que estes valores precisam ser fomentados para uma cultura de respeito, tolerância e paz.

\section{RESULTADOS E DISCUSSÕES}

O documentário visa ainda vir de encontro dos anseios de uma comunidade acadêmica que ainda não sabe, de modo geral, como transitar e lidar com as questões de gênero. Disponibilizado gratuitamente para ser exibido nos átrios dos centros de ensino e/ou salas de aula, a aproximação dialógica do vídeo abre espaços para o argumento e a compreensão, desejoso ainda de ser entendido como um alento, uma voz, a todo e qualquer grupo de menor representatividade.

\section{CONSIDERAÇÕES FINAIS}

O documentário faz uma crítica a diversos preconceitos, com destaque aos de gênero. Levar um instrumento audiovisual para a sala de aula é uma ótima estratégia para os professores conseguirem discutir com os alunos temas da atualidade, fatos históricos, drogas, gênero, saúde, meio ambiente e outros vieses. Como visto, desde o início do século XIX os problemas sociais ganham destaque pelo olhar do documentarista, que vê na sua intervenção uma forma de interferir 
socialmente nas condições do mundo. Seu olhar, quando ético e transparente, dá abertura para aqueles que, de outra forma, não teriam um espaço de manifestação própria e quase autoral.

Em um momento histórico de revisionismo dos papeis sociais, passa a ser de grande importância o estabelecimento de novos modelos de valores (como a tolerância, o respeito e a empatia), que darão bases à relação de confiança que o indivíduo tece com o panorama social que se avizinha. Em especial, na sociedade hipermidiática em que o indivíduo só existe se aparece e se é reconhecido midiaticamente.

Neste sentido, o documentário Maria Luisa pretende ser um instrumento que conta parte da trajetória de vida de uma mulher transgênero e dos desafios que enfrentou em vários momentos da vida e setores da sociedade, mas como também foi batalhadora na busca de seus direitos, pensando ainda em prol de um grupo maior. Além disto, mostra que precisamos ter mais tolerância e respeito com as pessoas que apenas querem ter o direito de ser quem são.

Cada vez mais se compreende que não é possível viver todas as facetas que o mundo oferece, e daí a importância da valorização e o resgate da memória, do passado, trazendo uma compensação àquilo que nos escapa, ou seja, ao ritmo acelerado do cotidiano das mudanças, quase uma resistência à perda dos antigos modos de viver e de exercer a cotidianidade.

Para tanto, o professor deve conhecer esse tipo de suporte, garantindo um conhecimento prévio dos mesmos, antes de levá-los para a sala de aula. É importante o uso de materiais alternativos que sirvam de motivação para os alunos, levando-os a uma concentração maior, bem como a um desenvolvimento crítico e cultural. Os docentes podem utilizar esses recursos tanto para trabalhar os conteúdos a serem ministrados com os estudantes, como para complementar sua própria formação.

\section{REFERÊNCIAS}

Bernardet, J. C. (1985). Cineastas e imagens do povo. São Paulo: Brasiliense.

Bodstein, Celso. (2016). O Documentário no Jornalismo. PUC Campinas. Recuperado de https://www.puc-campinas.edu.br/artigo-puc-campinas-entre-documentario-e-jornalismo.

Cruz, G. A. (2011). A construção biográfica no documentário cinematográfico: uma análise de Nelson Freire, Vinicius e Cartola: Música para os olhos. (Dissertação de Mestrado). Escola de Belas Artes, Universidade Federal de Minas Gerais, Minas Gerais, Brasil.

Fischer, R. M. B. (2007). Mídia, máquinas de imagens e práticas pedagógicas. Revista Brasileira de Educação, 12(35), pp. 290-299.

França, A. (2010). Cinema documentário e espectador em cena. LOGOS 32 - Comunicação e Audiovisual (UERJ). Ano 17, № 01, pp. 5-16.

Gelatti, M. L. G. (2017, abril 05). Relato inicial para documentário. Entrevistado por A. B. Narvaes. 
Marcato, T. M. (2014). O sujeito no documentário torna-se o sujeito do documentário. São Paulo: ABCine.

Nichols, B. (2005). Introdução ao documentário. Campinas: Papirus.

Ramos, F. P., Catani, A. (2001). Estudos De Cinema. Porto Alegre: Sulina.

Ramos, F. P. (2008). Mas afinal... o que é mesmo documentário? São Paulo: Senac.

Siqueira, V. H. F., Oliveira, C. M., Braga, J. O. (2005). O cinema e a formação docente: um diálogo sobre as questões de gênero. Comunicação \& Educação, N. 2.

Silva, J. D. (2018, setembro 24). Teaser do documentário Maria Luisa. [Arquivo de vídeo]. Recuperado de https://www.youtube.com/watch?v=W1uyQX15JWQ\&feature=youtu.be. 